\title{
ENCRUCIJADAS SERRANAS, FORMA URBANA Y SOPORTE NATURAL El impacto ambiental de la ciudad extendida. Río Ceballos
}

\author{
Arq. Cecilia Becerra \\ Universidad Nacional de Córdoba, Facultad de Arquitectura Urbanismo y Diseño \\ Director: Dr. Fernando Díaz Terreno Codirector: Mgtr. Cristian Terreno \\ paraceciliabecerra@hotmail.com
}

\section{RESUMEN}

El proceso de metropolización en Córdoba ha motivado procesos de transformación territorial en los centros urbanos de Sierras Chicas y en particular en la localidad de Río Ceballos. Como resultado de las migraciones internas desde la capital, la localidad de estudio presenta un constante incremento de la tasa de crecimiento intercensal $(2,5 \%)$.

Estos procesos -caracterizados por el crecimiento urbano en extensión con baja densidad habitacional- han determinado modos de ocupación del territorio con elevada presión en el soporte natural. Se manifiesta un deterioro de las cualidades paisajísticas y pérdidas de recursos y servicios ambientales.

En este contexto la investigación se propone reconocer el impacto ambiental de los modos de ocupación actuales. A partir de la definición de indicadores de impacto y la elaboración de cartografías que integran formas urbanas y soporte natural -vegetación, suelo, hidrografía, topografía, etc.- es posible interpretar y valorar las transformaciones en el territorio serrano.

Palabras clave: metropolización, extensión urbana, impacto ambiental

\begin{abstract}
The metropolization process in Córdoba has motivated territorial transformations in small cities of Sierras Chicas and, in particular, the town of Río Ceballos. As result of the internal migrations from the Capital this town shows a constant increase of the intercensal growth rate $(2.5 \%)$.

These transformations -characterized by urban growth in extension with low housing density- have determined occupation modes of the territory with high pressure on the natural support. There is a deterioration of the landscape qualities and loss of environmental resources.

In this context, the research aims to recognize the environmental impact of current occupation modes. It is possible to interpret and value the transformations in the mountain territory working with the definition of impact indicators and the elaboration of cartographies that integrate urban forms and natural support vegetation, soil, hydrography, topography, etc.
\end{abstract}

Keywords: metropolitanization, urban extension, environmental impact 


\section{INTRODUCCION}

\subsection{El proceso de crecimiento urbano por extensión en Río Ceballos}

En el Área Metropolitana Córdoba, Tecco y Fernández (2002) explican que la delimitación entre la ciudad y su entorno natural se ha desdibujado, manifestándose la dispersión urbana a partir del intenso flujo de transporte que conecta cada vez un espacio mayor. Se constata un crecimiento de las poblaciones periféricas en detrimento del crecimiento del centro de la ciudad.

El crecimiento de la población en Sierras Chicas es un fenómeno que se profundiza desde hace tres décadas, según lo revelan los datos censales de los años 1980-1991-2001-2010. La década del 80 manifiesta el inicio del proceso de metropolización y el proceso migratorio centrífugo desde la ciudad principal hacia localidades satélites. Río Ceballos manifiesta una tasa de crecimiento intercensal del 2,65\%. El estudio del proceso de crecimiento urbano de la localidad en el período 1990- 2017 evidencia modos característicos de ocupación. En primer lugar, la baja densidad de población que oscila entre 15 y 19hab/ha, verificándose gran cantidad de parcelas urbanizadas no ocupadas; Luego la extensión de la superficie urbanizada que se ubica linealmente sobre cauces de ríos y vías principales con crecimientos de trama hacia el este (llanura) y oeste (piedemonte); En tercer lugar la dispersión urbana, a partir de áreas urbanizadas que no logran completamiento de trama y lo edificado se presenta esparcido en el territorio; $Y$ finalmente la discontinuidad de la trama urbana, con extensiones urbanas - vinculadas a nuevas vialidadesdesarticuladas del área urbana existente, y alejadas del núcleo urbano central.

La geomorfología del territorio y la hidrografía resultan centrales en la configuración urbana. La implantación particular en la transición del faldeo serrano y la llanura determina una ocupación lineal sobre la ladera serrana y los cauces de ríos y arroyos. Hasta 1990, puede verificarse esta conformación que prioriza la accesibilidad vial, la continuidad con la trama existente y la ocupación de áreas de menor pendiente, dando como resultado una mancha urbana continua. A partir del 2002 el soporte natural deja de ser un limitante a la urbanización, avanzando sobre laderas con fuertes pendientes. Las expansiones de la trama urbana avanzan hacia el oeste, en áreas de piedemonte serrano sobre áreas pertenecientes a cuencas hídricas.

La ejecución de obras de vialidad a escala metropolitana- regional es determinante en los procesos de migración interna hacia la localidad, acelerando la ocupación de sectores colindantes -urbanizaciones Ruta Provincial E53 y Camino al Cuadrado-.

Finalmente, cabe destacar que la trama urbana existente aún tiene capacidad de albergar población a partir de completamiento de sectores vacantes. La misma puede contener un crecimiento de más del doble de la población actual, sin avanzar sobre áreas no urbanizadas.

\subsection{Problemáticas ambientales en la ciudad serrana extendida}

La ciudad que hemos caracterizado anteriormente como ciudad serrana extendida -de baja densidad, dispersa y discontinua- se presenta como una forma de desarrollo no sostenible a medio-largo plazo ya que el consumo de suelo excesivo produce un alto impacto en el hábitat serrano. Asimismo, debido a su extensión y a sus umbrales de densidades relativamente bajos supone altos costos de infraestructuras y de gestión de los servicios urbanos.

Las extensiones urbanas sobre zonas rurales, o áreas naturales de alta fragilidad ambiental -cuencas hídricas, cauces de arroyos, laderas serranas, reservas de flora y fauna nativa- sin consideración del soporte natural, han ocasionado pérdidas de recursos y servicios ambientales. Se evidencia una presión sobre el ecosistema, el cual ya manifiesta su fragilidad: inundaciones, incendios, deforestación de bosque nativo, pérdida de cobertura vegetal y suelos, crisis hídrica, entre otras.

En particular el uso urbano ha ocasionado contaminación de aguas superficiales y subterráneas por líquidos cloacales no tratados debido a que la ciudad no presenta red cloacal y en muchos casos se utilizan sistemas inadecuados. Así mismo se evidencian modos de ocupación de suelo urbano de alto impacto movimiento de suelo natural, cortes abruptos en laderas, deforestación o alteración de cobertura vegetal y del suelo natural, impermeabilización de suelo- que profundizan procesos erosivos. Estas prácticas significan a su vez transformaciones antrópicas en sistemas hidrológicos naturales: modificación de escorrentías naturales, invasión de la urbanización en líneas de ribera o cauces de arroyos, rectificación de cauces, achicamiento de lechos.

La crisis hídrica ha demostrado graves conflictos en la provisión del agua potable para una población que se manifiesta en constante aumento. A nivel local, el clima ha oscilado entre períodos de lluvia y otros de sequía extrema, evidenciándose un fuerte riesgo de inundabilidad de las zonas urbanas de ribera como resultado de las intensas lluvias de Febrero 2015. 


\section{ENFOQUE CONCEPTUAL Y METODOLOGICO}

\subsection{El territorio como soporte natural. Capacidad de acogida. Aptitud o Impacto.}

Para realizar una valoración de las problemáticas ambientales en el contexto de los procesos de crecimiento urbano por extensión, resultan pertinentes algunos conceptos y metodologías desarrollados en los Estudios de Impacto Ambiental. Según Gómez Orea (2013) la capacidad de acogida de un territorio representa la relación del medio con las actividades humanas y se refiere al grado de idoneidad, es decir al mejor uso que puede hacerse del medio teniendo en cuenta su fragilidad y su potencialidad. En este sentido, expresa la concertación entre el punto de vista del entorno y el de la actividad; concertación en términos de impacto de la actividad, y de aptitud del territorio.

La aptitud territorial de una actividad humana se refiere al comportamiento del entorno -en este caso soporte natural- para con la actividad y se puede definir como la medida en que el entorno cubre los requisitos locacionales de la actividad. Por su parte, el impacto territorial se vincula a los efectos de una actividad en el entorno. El primero incorpora la cualidad de "potencialidad" del territorio, el segundo la de "fragilidad" del mismo.

Un antecedente a los estudios de impacto ambiental, lo constituye el trabajo pionero desarrollado por lan McHarg (2000), quien propone una interpretación del territorio a partir del análisis de idoneidad (suitability analysis). Este estudio permite indagar sobre las oportunidades intrínsecas y las limitaciones existentes para el desarrollo urbano en un territorio determinado. El autor, incorpora un proceso interdisciplinar de recogida de datos sobre diversos componentes naturales -geología, pendientes, hidrología, vegetación, vida salvaje- y culturales -valores del paisaje, sitios históricos, etc-. Esta información se representa en mapas que permiten la distribución espacial de la información, los cuales se estructuran en capas y se superponen o combinan para identificar los valores del paisaje, las limitaciones y oportunidades de los usos potenciales. El análisis que se pretende abordar requiere una aproximación operativa al concepto "soporte natural" que lo concrete en un conjunto de variables susceptibles de ser inventariadas, medidas, valoradas de acuerdo a los problemas y oportunidades ambientales que presenta el territorio de estudio. Gómez Orea (2013) se refiere a tales variables como factores ambientales: el ser humano, la fauna y la flora; el suelo, el agua, el aire, el clima y el paisaje; los bienes materiales y el patrimonio cultural.

\subsection{Aspectos metodológicos}

El territorio de estudio forma parte de las cuencas de la Ladera Oriental de las Sierras Chicas -subcuenca del arroyo Saldán-. Según Deón (2015:3) "una cuenca es un sistema complejo y dinámico que incorpora bosque, agua, fauna y territorio, en constante dependencia, contacto e interrelación".

Con el objetivo de evaluar la capacidad de acogida del territorio de estudio se define una unidad ambiental de análisis delimitada por un polígono de subcuencas: La Quebrada, Manantiales, Río Ceballos Norte y Río Ceballos Sur; subcuenca del Río Salsipuedes y subcuenca sector Ruta E53. Este recorte ambiental integra el área urbana de Río Ceballos.

La actividad a partir de la cual se analiza el territorio se define como uso de suelo urbano: residencial de baja densidad. En función de las principales problemáticas ambientales detectadas se seleccionan tres factores ambientales que resultan pertinentes para el análisis de capacidad de acogida del soporte natural serrano: suelo, agua y vegetación.

Sobre estos tres factores se definen indicadores de impacto ambiental según el siguiente cuadro:

\begin{tabular}{|l|l|l|l|l|}
\hline $\begin{array}{l}\text { FACTOR } \\
\text { AMBIENTAL }\end{array}$ & $\begin{array}{l}\text { CARTOGRAFIAS } \\
\text { ESTADO SITUACION }\end{array}$ & & $\begin{array}{l}\text { INDICADORES DE IMPACTO } \\
\text { VARIABLES ESTUDIO }\end{array}$ & $\begin{array}{l}\text { CARTOGRAFIAS DE } \\
\text { IMPACTO }\end{array}$ \\
\hline VEGETACION & COBERTURA VEGETAL & 1 & $\begin{array}{l}\text { TIPO DE COBERTURA EXISTENTE } \\
\text { Tipo cobertura+ consolidación urbana }\end{array}$ & $\begin{array}{l}\text { MAPA IMPACTO S/ } \\
\text { COBERTURA VEGETAL }\end{array}$ \\
\hline SUELO & GEOLOGIA & 2 & $\begin{array}{l}\text { PERMEABILIDAD } \\
\text { MAPA PERMEABILIDAD }\end{array}$ & $\begin{array}{l}\text { MAPA IMPACTO S/ } \\
\text { PERMEABILIDAD }\end{array}$ \\
\cline { 2 - 5 } & \multirow{2}{*}{ GEOMORFOLOGIA } & 3 & $\begin{array}{l}\text { PENDIENTES } \\
\text { MAPA PENDIENTES }\end{array}$ & $\begin{array}{l}\text { MAPA IMPACTO S/ } \\
\text { PENDIENTES }\end{array}$ \\
\cline { 2 - 5 } & 4 & $\begin{array}{l}\text { EROSIONABILIDAD } \\
\text { Permeabilidad+ pendiente+ Veg. } \\
\text { MAPA EROSIONABILIDAD }\end{array}$ & $\begin{array}{l}\text { MAPA IMPACTO S/ } \\
\text { EROSIONABILIDAD }\end{array}$ \\
\hline AGUA & $\begin{array}{l}\text { CURSOS DE AGUA } \\
\text { SUPERFICIALES }\end{array}$ & 5 & $\begin{array}{l}\text { INUNDABILIDAD } \\
\text { MAPA RIESGO HIDRICO }\end{array}$ & $\begin{array}{l}\text { MAPA IMPACTO S/ } \\
\text { RIESGO HIDRICO }\end{array}$ \\
\hline
\end{tabular}


Teniendo en cuenta la metodología desarrollada por Mc Harg (2000), se propone realizar cartografías ambientales del polígono de estudio según los factores seleccionados. Los mapeos incluyen estudios interdisciplinarios previos y vinculan la mancha urbana actual con las variables de estudio del soporte natural permitiendo detectar niveles de impacto de la actividad residencial.

Se toma como referencia bibliográfica la investigación desarrollada por Terreno (2010) para el área de estudio, quien propone -a partir de la metodología multicriterio- diversas matrices de evaluación de aptitud e impacto territorial para la actividad residencial. Si bien estas matrices fueron desarrolladas para el análisis de unidades territoriales de menor superficie -loteos-, la metodología puede aplicarse a polígonos mayores. De esta manera, las matrices son adaptadas y completadas para la escala de estudio.

\section{EL SOPORTE NATURAL SERRANO}

\subsection{Vegetación}

\subsubsection{Caracterización de Cobertura Vegetal.}

El área de estudio está ubicada en el Dominio Chaqueño, según la descripción realizada por Gavier y Bucher (2002), la vegetación nativa en Sierras Chicas presenta los siguientes pisos altitudinales: a) bosque de llanura pedemontana, b) bosque serrano, c) arbustal y d) pastizal de altura. El bosque de llanura pedemontana se ubica bajo los $750 \mathrm{~m}$ y está dominado por quebracho blanco, aunque por acción antrópica, se verifica un incremento de espinillo, aromo, garabato y algarrobo. El bosque serrano se extiende entre los 700 y $1150 \mathrm{~m}$ y está dominado por molle, con presencia de tala y coco. Es un bosque con un 30 a $60 \%$ de cobertura, alcanzando hasta el $70 \%$ en algunas quebradas y valles protegidos. El arbustal se ubica entre los 1000 y $1100 \mathrm{~m}$ y presenta especies de romerillo, chilca y salvia. En muchos lugares el arbustal reemplaza al bosque serrano donde éste ha sufrido algún disturbio como fuego o sobrepastoreo. El pastizal de altura se encuentra en cumbres y planicies por encima de los 1100m con dominio de gramíneas.

\subsubsection{Deforestación y fragmentación de bosque nativo}

Un problema central vinculado al crecimiento urbano por extensión, es la deforestación y fragmentación de la cobertura vegetal en las áreas serranas. Gavier y Bucher explican que "La deforestación no sólo implica la eliminación total de las masas boscosas sino también su fragmentación, proceso por el cual un área continua de bosque resulta dividida en fragmentos menores aislados entre sí por una matriz de tierras con otro tipo de cobertura -por ejemplo, vegetación arbustiva, cultivos, áreas urbanas, etc-. La fragmentación constituye una de las mayores amenazas para la biodiversidad" (2002:4).

La deforestación en Sierras Chicas tiene efectos ambientales adversos, tanto sobre los servicios como sobre los bienes ambientales. Gavier y Bucher resaltan que algunos de los servicios más importantes provistos por el bosque son: El control de erosión y alimentación de acuíferos; El mantenimiento de biodiversidad; El balance atmosférico del carbono. Sobre los Bienes ambientales se destaca la calidad paisajística, considerando al bosque serrano como un componente fundamental del atractivo paisajístico de las Sierras Chicas. Los bosques constituyen una de las bases de la actividad turística de la región.

Deón (2015) explica que la introducción de vegetación exótica no facilita e igual medida que la nativa la infiltración del agua y la fijación del suelo con sus raíces. El reemplazo de vegetación -por siempre verdes, grateus, sauces, pinos, etc.- modifica las escorrentías ya que no absorbe el agua hacia el subsuelo en igual cantidad que el bosque nativo.

Respecto a los índices de deforestación, la investigación de Gavier y Bucher indica que durante el período 1970-1997 desaparecieron alrededor de 5759 ha de bosque en Sierras Chicas -alrededor de un 40\%- a una tasa anual de 1,8\%. La pérdida de masa boscosa fue un $22 \%$ mayor en la llanura pedemontana que en la sierra. Las áreas deforestadas se asocian con las áreas urbanas y las rutas principales, concentrándose principalmente sobre una franja entre la sierra y la llanura pedemontana, afectando y aislando ambas subunidades. Agudelo (2016) analiza la deforestación para el período 1997-2009, destacando que en 1997 las Sierras Chicas tenían 15.320 hectáreas de bosques nativos, mientras que en 2009 el cálculo arrojó 11.780 , es decir la zona perdió 4.330 hectáreas. Esto significa que la tasa de deforestación anual se ha incrementado de $1,8 \%$ al 2,2\%. A partir de este índice Agudelo proyecta que para 2025 el bosque nativo se reduciría a 8751 hectáreas y para el 2050 sólo se conservarían 5728 hectáreas.

\subsubsection{Indicadores de impacto ambiental: Cobertura Vegetal en Radio Urbano}

Para evaluar el impacto de uso urbano en relación a la cobertura vegetal existente, se toma como referencia el mapa de Análisis de Cobertura Vegetal sobre la Provincia de Córdoba (2016). Este mapa distingue cuatro 
categorías de cobertura vegetal: Bosques, matorrales, roquedales y pastizales. Las dos últimas no incluidas en sector de estudio. El uso cultural se referencia a áreas urbanas y rurales sin cobertura vegetal.

La cartografía de impacto de uso urbano sobre vegetación existente se realiza a partir de la superposición del área urbana (radio actual) y el mapa de análisis de cobertura. Los niveles de impacto se definen a partir del tipo de cobertura y luego por el grado de consolidación urbana que poseen las áreas. Esta distinción resulta necesaria para evaluar -a futuro- la posibilidad de conservación de las mismas.

\begin{tabular}{|l|l|l|l|}
\hline Tipo Cobertura & Grado consolidación urbana & Porcentaje s/ Tipo Cobertura* & Nivel de Impacto \\
\hline \multirow{4}{*}{ Bosques } & Loteado en consolidación & $13 \%(350 \mathrm{ha})$ & ALTO \\
\cline { 2 - 3 } & Loteado no consolidado & $20 \%(550 \mathrm{ha})$ & \\
\cline { 2 - 3 } & Sin lotear & $5,7 \%(155 \mathrm{ha})$ & \\
\hline \multirow{3}{*}{ Matorrales } & Loteado en consolidación & $21 \%(570 \mathrm{ha})$ & \\
\cline { 2 - 3 } & Loteado no consolidado & $0,8 \%(22 \mathrm{ha})$ & \\
\cline { 2 - 3 } & Sin lotear & $3,5 \%(95 \mathrm{ha})$ & \multirow{2}{*}{ BAJO } \\
\hline Cultural & Consolidado sin cobertura & $36 \%(958 \mathrm{ha})$ & \\
\hline
\end{tabular}

Impacto según cobertura vegetal. Fuente: Elaboración propia

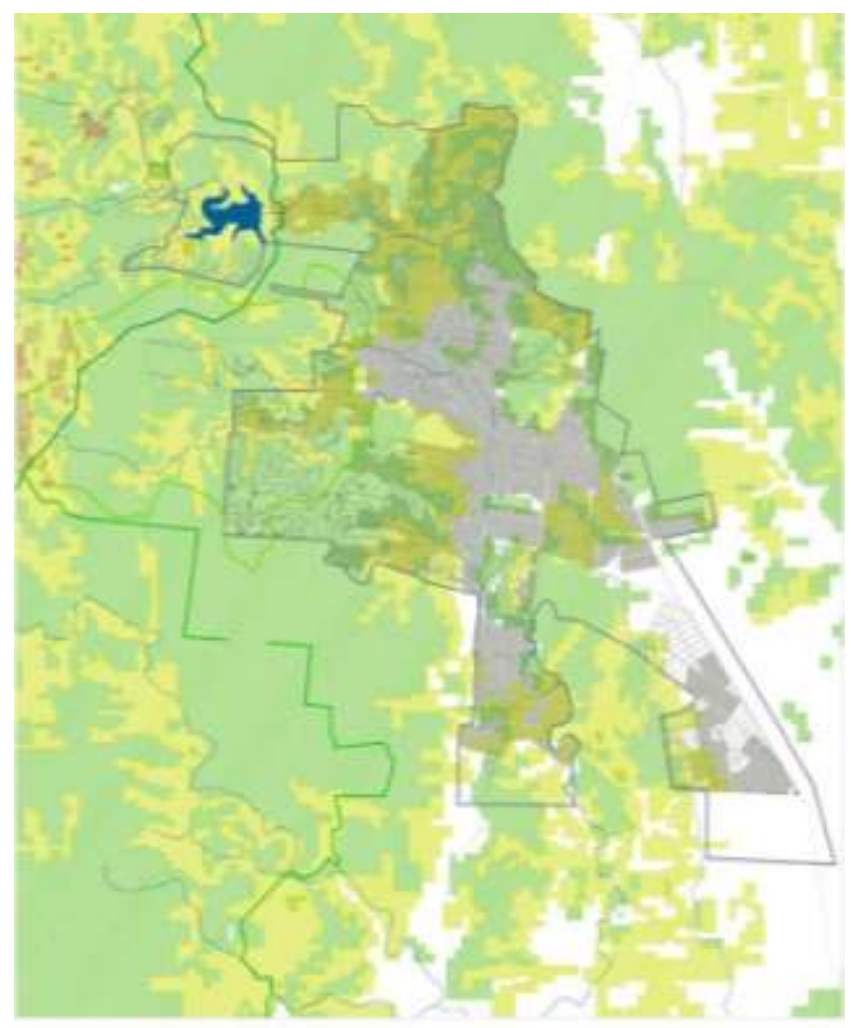

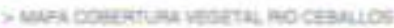

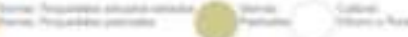

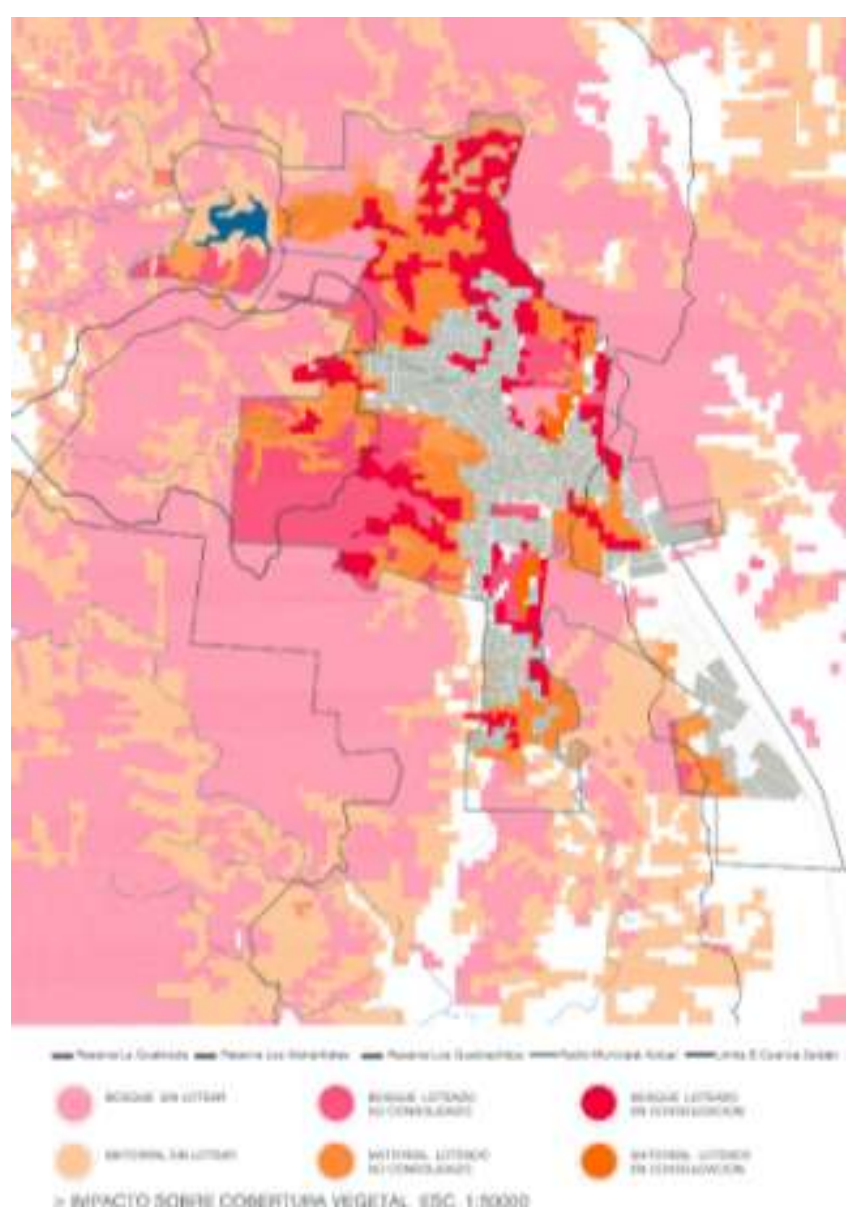

Cartografía impacto uso urbano según cobertura vegetal. Fuente: Elaboración propia

\subsubsection{Cartografía de Impacto según Cobertura Vegetal existente}

La cartografía de impacto de uso urbano en relación a la cobertura vegetal pone de manifiesto que la superficie con cobertura vegetal dentro del radio urbano es significativa: el 64\% (1742ha) aun cuenta con cobertura vegetal (bosques y matorrales) mientras que el 36\% (958 ha) posee uso urbano (cultural) sin vegetación. Sin embargo, estas áreas con cobertura se encuentran en su mayoría (85\%) loteadas lo cual significa una amenaza para su conservación. En algunos casos presentan incipiente consolidación y en otros son loteos sin consolidación urbana. Dentro de las áreas con cobertura el $38,7 \%$ son bosques y el $25,3 \%$ son matorrales.

A partir de la cartografía elaborada, una de las áreas que presentaría mayor impacto de uso urbano por la presencia de cobertura vegetal es el polígono que forma parte de la Reserva Los Manantiales -Ñu Pora y 
Manantiales-y se ubica al oeste. Integra principalmente áreas de bosque -loteadas no ocupadas- y se destaca por su extensa superficie como parte del corredor de reservas naturales. El mapa permite evidenciar diversas situaciones donde la urbanización amenaza la continuidad del bosque.

\subsection{Suelo}

\subsubsection{Caracterización Geológica}

Como marco general, para comprender la estructura geológica del área de estudio se toman las investigaciones realizadas por Cioccale (1999) y Barbeito et al. (2009) para la Cuenca del Arroyo Saldán. La zona de estudio corresponde al Dominio Serrano, en el cual, la distribución de los diferentes tipos de suelo está condicionada por las pendientes, el clima y el material parental, provocando grandes variaciones en espacios muy reducidos. "En las partes con relieve más abruptos se intensifican los procesos erosivos, los afloramientos rocosos y suelos muy someros dominan el paisaje. Mientras que donde las condiciones de pendiente lo permiten, los suelos están formados por una sucesión de capas aluviales o coluviales con texturas francas a arenosa franca, con porcentajes de gravas y gravillas superiores a $20 \%$ que varían irregularmente en toda su profundidad" (Cioccale, 1999:58) .

Se presentan tres sectores diferenciados: hacia el oeste la serranía correspondiente a la vertiente este de la Sierra Chica, luego el piedemonte oriental y finalmente una planicie de escasa pendiente al este.

Barbeito et al. (2009) explican que los relieves iniciales han sido y son modelados por procesos exógenos denominados morfodinámicos, responsables del modelado del paisaje. Tales procesos se corresponden principalmente en el área de estudio- con la acción del escurrimiento superficial generado por los aportes pluviales que ocasionan erosión hídrica laminar. Su intensidad depende de la naturaleza geológica, del relieve, del grado de protección de la vegetación natural y del clima, de acuerdo al tipo, intensidad y frecuencia de las precipitaciones.

En las laderas los suelos son someros, sueltos, pedregosos y de bajo contenido orgánico con fuerte susceptibilidad a la erosión hídrica. Si al escurrimiento se suma una cubierta de vegetación alterada, se ocasiona una progresiva pérdida de partículas finas por lavado, y un aumento de la pedregosidad. En el fondo de los valles el aporte de los excedentes derivados de las laderas, adquieren concentración y frente a ausencia o alteración de la cubierta vegetal, se generan procesos de erosión hídrica. Todo esto significa un cambio en la relación escorrentía /infiltración original, con sustancial aumento de la primera, en detrimento de la segunda.

Como consecuencia hay un aumento de los caudales de escorrentía y del aporte de sedimentos al sistema de drenaje, lo que involucra un incremento en la magnitud de las inundaciones y la acumulación de sedimentos en obras de desagüe, calles en las zonas urbanas, etc.

\subsubsection{Permeabilidad}

El suelo tiene un rol de amortiguador ya que se se comporta como filtro y elemento transformador entre la atmósfera y la capa freática. Permite retener y procesar los contaminantes que lleguen a evitando su paso directo al agua, a la vegetación o al hombre. Asimismo, el suelo posee la capacidad de retener el agua de lluvia que después soltará poco a poco hacia la capa freática, interviniendo en la regulación hidrológica (Gómez Orea, 2013).

La permeabilidad del suelo es una característica clave para evaluar el impacto del uso urbano, ya que en el área de estudio se evidencian ciclos pluviales que oscilan entre períodos de crisis hídrica y otros con abundantes precipitaciones. En los períodos de lluvia, la permeabilidad determina la capacidad del suelo de retener el agua y liberarla paulatinamente hacia los cauces a través del dinámico proceso hidrológico que se da en las sucesivas capas del suelo. De esta manera se evita la escorrentía superficial, y se previenen los procesos erosivos. En los períodos de sequía el suelo permeable permite procesos de recarga de acuíferos (Deón, 2015).

Para la elaboración de cartografías de impacto del uso urbano en el suelo serrano se toma como referencia la clasificación geológica y cartografía elaborada por Cioccale (1999) para la zona de estudio. La superposición del mapa geológico con la mancha urbana actual, permitirá evaluar el impacto territorial según permeabilidad del suelo.

\begin{tabular}{|c|c|c|}
\hline Tipo suelo & Características y Permeabilidad & \begin{tabular}{|l} 
Nivel \\
Impacto
\end{tabular} \\
\hline $\begin{array}{l}\text { Granitos } \\
\text { granitoides }\end{array}$ & $\begin{array}{l}\text { Se presenta como una roca fuerte, dependiendo del grado de } \\
\text { meteorización. Las rocas graníticas por la pasividad del material (sin } \\
\text { esquitosidad), la débil y discontinua capa de suelos residuales que }\end{array}$ & MUY ALTO \\
\hline
\end{tabular}




\begin{tabular}{|l|l|c|}
\hline & $\begin{array}{l}\text { soportan y los elevados porcentajes de roca desnuda son las menos } \\
\text { permeables }\end{array}$ & \\
\hline $\begin{array}{l}\text { Gneis tonalítico } \\
\text { granitizado }\end{array}$ & $\begin{array}{l}\text { Presentan plutones varios y pequeños cuerpos graníticos que se } \\
\text { intruyen en el gneis. Su permeabilidad es muy baja. }\end{array}$ & ALTO \\
\hline $\begin{array}{l}\text { Gneis } \\
\text { Tonalítico }\end{array}$ & $\begin{array}{l}\text { Se encuentra meteorizado, se desmorona fácilmente formando una } \\
\text { arena de grano grueso. Presentan planos de debilidad por donde } \\
\text { atacan agentes erosivos, disgregándose con facilidad. Su } \\
\text { permeabilidad es baja. }\end{array}$ & MEDIO \\
\hline $\begin{array}{l}\text { Gneis } \\
\text { Esquistoso }\end{array}$ & $\begin{array}{l}\text { Debido a su estructura laminar tiende a fragmentarse en capas } \\
\text { delgadas. Su permeabilidad es baja. }\end{array}$ & MEDIO \\
\hline $\begin{array}{l}\text { Sedimentos } \\
\text { fluviales } \\
\text { coluviales. }\end{array}$ & $\begin{array}{l}\text { La cubierta sedimentaria con permeabilidad media- alta, infiltra } \\
\text { aceleradamente y posibilita un rápido escurrimiento hídrico hacia } \\
\text { partes bajas del valle. Poseen una textura media, limoloessico y } \\
\text { deposito fluviotorrencial. Su permeabilidad es media-alta. }\end{array}$ & MUY BAJO \\
\hline $\begin{array}{l}\text { Conglomerado } \\
\text { Saldán }\end{array}$ & $\begin{array}{l}\text { Está compuesta por conglomerados, areniscas y fangolitas de } \\
\text { coloración rojiza. Se distinguen dos facies, una de brechas macizas } \\
\text { matriz soportadas y otra de conglomerados arenosos con } \\
\text { estratificación cruda, constituido por material detrítico muy grueso } \\
\text { (Gneises, anfibolitas, mármoles, tonalitas). Su permeabilidad es } \\
\text { media. }\end{array}$ & BAJO \\
\hline
\end{tabular}

Impacto Territorial según permeabilidad del suelo. Completamiento para Área de Estudio a partir de Terreno (2010)

\subsubsection{Cartografía de Impacto según permeabilidad del suelo}

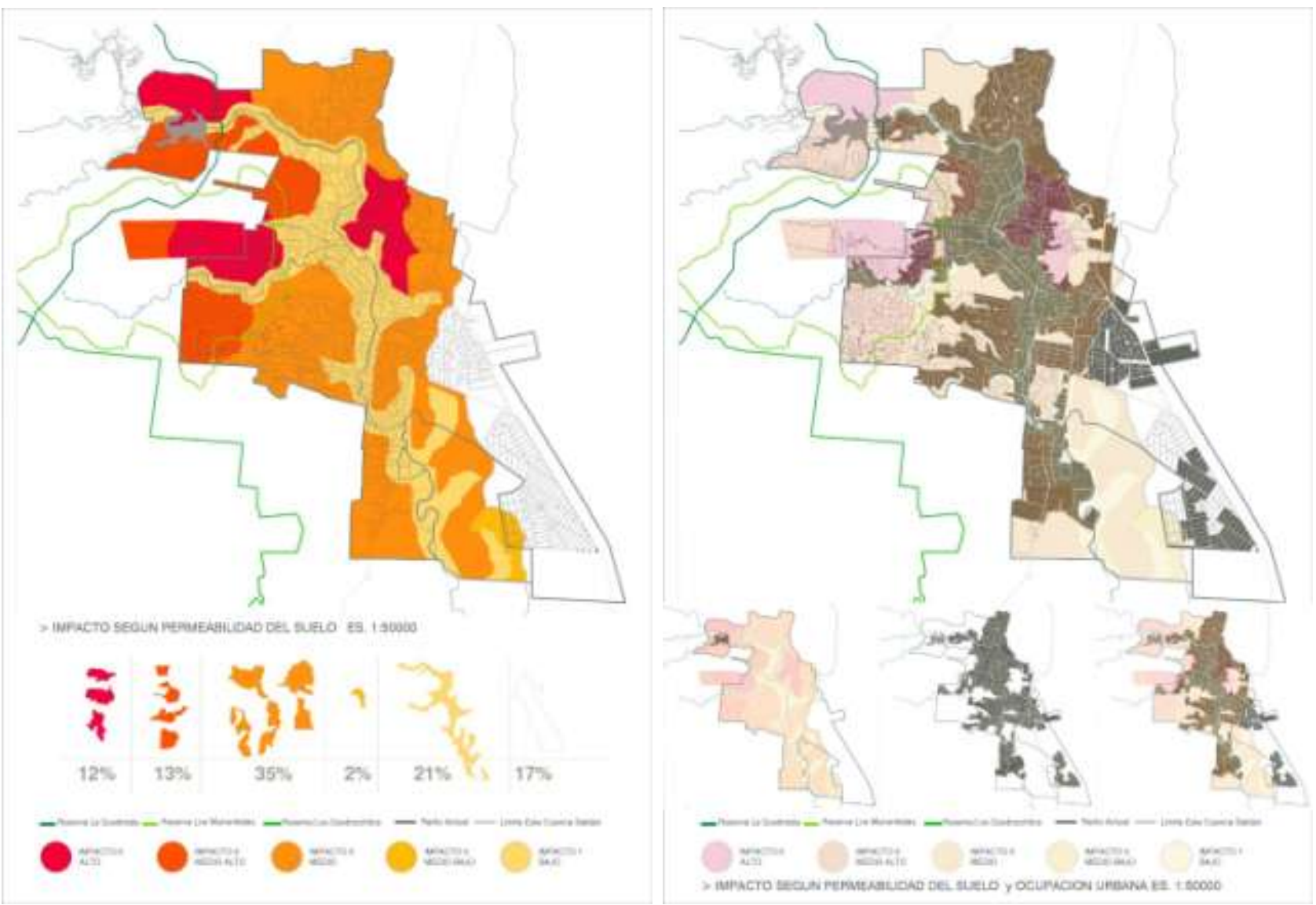

Cartografía impacto uso urbano según permeabilidad de suelo. Fuente: Elaboración propia

Las áreas que presentan mayor impacto para uso urbano por su baja permeabilidad y alto escurrimiento son las formaciones de granitos y granitoides. En el sector de estudio existen tres formaciones de granitos: el polígono que abarca el noreste de la Reserva Hídrica Los Manantiales -con baja ocupación parcelaria-; luego un área al norte del Dique La Quebrada -sin parcelamiento urbano-; y finalmente un sector que se delimita tomando como eje la calle Sarmiento y presenta mayor consolidación urbana. Las formaciones de 
Gneis Tonalítico Granitizado -cuyo impacto de uso urbano es alto -, se corresponden con sector oeste de la localidad, piedemonte serrano, y forma parte de la Reserva Los Manantiales, y de la Reserva La Quebrada. Son áreas de borde urbano, mayormente parceladas pero con baja consolidación.

Luego se observa que el Gneis Tonalítico, - impacto medio- ocupa la mayor extensión del área urbana de la localidad -parcelada y ocupada-.

\subsubsection{Caracterización Geomorfológica}

Dentro de la región de las Sierras Chicas -y según la clasificación desarrollada por Cioccale (1999)- la localidad de Río Ceballos está asentada sobre cuatro unidades del sistema geomorfológico de la pendiente estructural oriental. De oeste a este se suceden cuatro fajas contiguas que son: el Escarpe erosionado superior que presenta las morfologías más abruptas del sistema -con pendientes del 35 al $50 \%$ - y está limitado entre los $1125 \mathrm{~m}$ y $875 \mathrm{~m}$. Este sistema incluye el sector de Colanchanga, Dique y Reserva la Quebrada; El escarpe erosionado inferior se ubica entre los $875 \mathrm{~m}$ y los $750 \mathrm{~m}$-con pendiente comprendidas entre $20 \%$ y el $35 \%$ - e incluye gran parte del área urbana, al oeste de la localidad; El valle asimétrico de fondo plano, se ubica entre los $775 \mathrm{~m}$ en sector norte y $500 \mathrm{~m}$ en la confluencia con el Río Suquía. Este sistema ocupa una franja norte-sur que coincide con el trazado del Río Ceballos, y su valle fluvial. Muestra laderas abruptas al oeste y relieves bajos al este; Las lomas bajas de basamento y conglomerado se presentan con elevaciones moderadas a suaves al este del valle fluvial y pendientes medias del 12 al $20 \%$. El estudio de las pendientes resulta clave para evaluar el impacto del uso urbano del territorio. Según Gómez Orea (2013) la alteración del carácter topográfico constituye un impacto directo en sí mismo, particularmente si afecta un punto de interés geológico de valor cultural, o al paisaje, e indirecto si tiene repercusiones en el funcionamiento hidráulico del drenaje superficial. En el área de estudio, la falta de consideración de la topografía en el trazado urbano ha sido una constante, tanto en la red vial como en la forma de las parcelas. Esta indiferencia geomorfológica ha originado conflictos asociados a escorrentías, cortes abruptos e impermeabilización de laderas, desmoronamientos de taludes, procesos de erosión, entre otros. En muchos casos, la imposibilidad de consolidación de antiguos loteos se debe a que los trazados urbanos son incompatibles con la topografía serrana y por tanto las calles proyectadas son intransitables vehicularmente por su elevada pendiente. Así mismo se agregan las dificultades vinculadas a la provisión de infraestructuras, y al encarecimiento de los costos de construcción.

\subsubsection{Pendientes}

Para evaluar el impacto del uso urbano en relación a las pendientes del territorio, se toma como referencia los valores propuestos por Terreno (2010). Se establece que si bien en las pendientes entre el 15 y el $20 \%$ los desarrollos urbanos deberían evitarse, éstos pueden realizarse a partir de estudios especiales de impacto sobre el soporte natural. Sin embargo en pendientes mayores al $25 \%$ se desestima completamente su ocupación urbana por su alto riesgo de erosión (McHarg, 2000). Otra investigación geológica referida al área de estudio (Villoslada, 2003) coincide con estos parámetros indicando que las zonas que presentan pendientes entre el 20 y el 35\% no soportan desarrollos urbanos continuos, siendo su condición a urbanizar limitada. Para las áreas con pendientes mayores al 35\% es necesario restringir la urbanización.

\begin{tabular}{|l|l|l|}
\hline Grado de Pendiente & Aptitud & Nivel Impacto \\
\hline 0 a $15 \%$ & Preferente o apto para urbanizaciones & BAJO- MEDIO \\
\hline 15 al $25 \%$ & Difícil, requiere estudios especiales & MEDIO-ALTO \\
\hline + de $25 \%$ & No apto & MUY ALTO \\
\hline
\end{tabular}

Impacto uso urbano según pendientes del suelo

\subsubsection{Cartografía de Impacto según pendientes del suelo}

Las áreas que presentan mayor impacto para uso urbano con pendientes superiores al $25 \%$ se ubican en la zona oeste del área de estudio, piedemonte serrano. Dentro de este grupo existen áreas loteadas y ocupadas que se localizan en la ladera norte y este de Ñu Pora, Terrazas de Río Ceballos y en la Reserva Los Manantiales -incluyendo los loteos El Vergel, Agua del Peñon y Los Manantiales-. En segundo lugar, las áreas con pendientes entre el 15 y el $25 \%$ se encuentran distribuidas en el territorio por tratarse de un área serrana. En algunos casos están integradas al área urbana consolidada y en otros forman parte de loteos 
inactivos. La cartografía evidencia que la mayor superficie de mancha urbana se extiende en las áreas con menores pendientes, a lo largo del valle serrano y acompañando los cursos de agua.

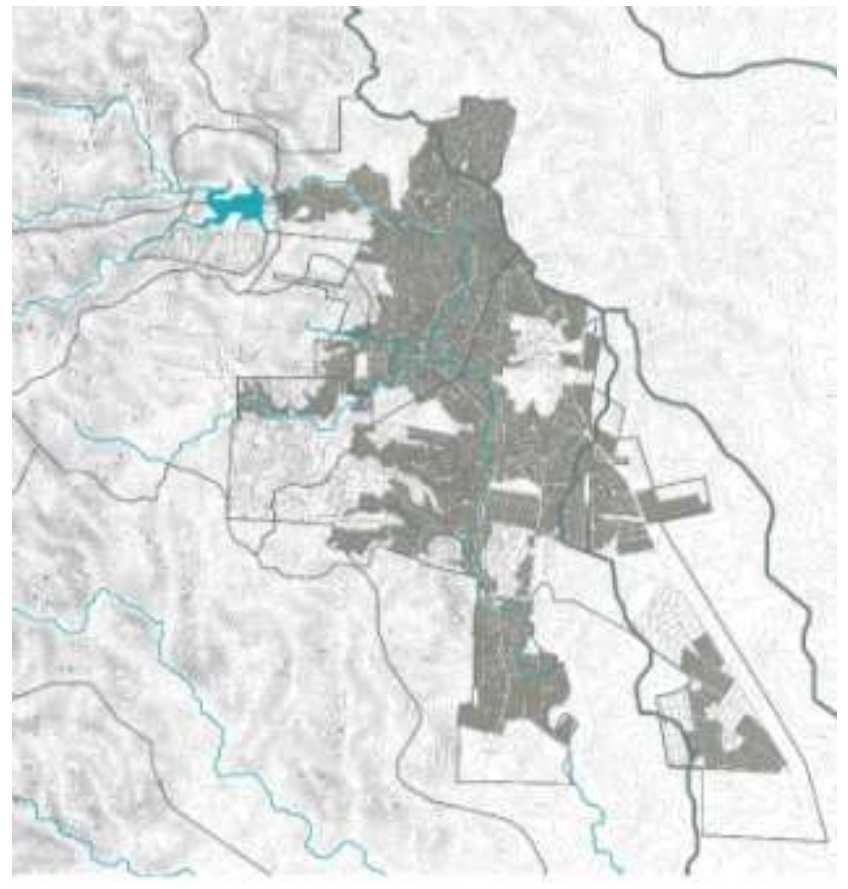

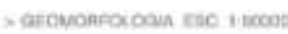

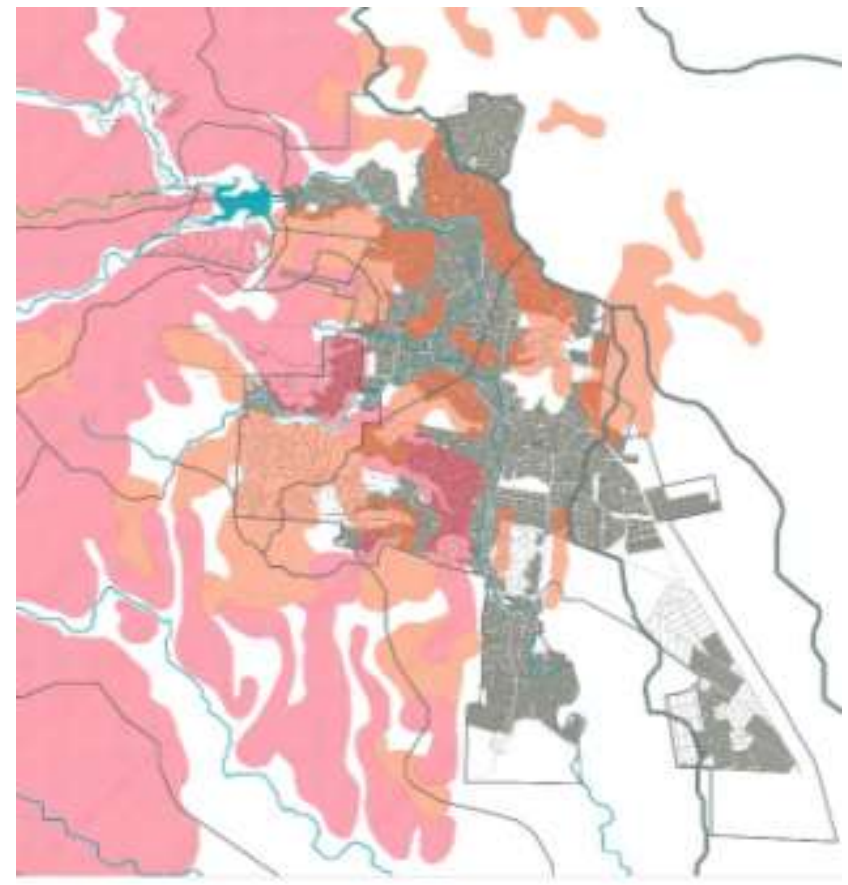

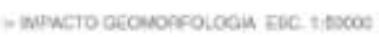

Cartografía impacto uso urbano según inundabilidad. Fuente: Elaboración propia

\subsubsection{Erosionabilidad}

En el área de estudio, los procesos de erosión son principalmente de origen hídrico, producidos por las escorrentías del agua de lluvia sobre las laderas serranas. La intensidad de estos procesos está vinculada a las pendientes, el tipo de cobertura vegetal y las características del suelo respecto a permeabilidad o retención de agua. En las áreas urbanas- serranas la erosión es uno de los procesos de degradación ambiental de mayor impacto generado por el desarrollo antrópico. La pérdida de cobertura vegetal originada por el crecimiento urbano y la ocupación de laderas o áreas con pronunciada pendiente agudizan el deterioro. Los efectos de la erosión se evidencian tanto a escala regional o de cuenca hídrica como a escala local sobre la ciudad construida: deterioro de las calles por escorrentías que remueven partículas de suelo, procesos de sedimentación en las zonas bajas. Asimismo se intensifica la inundabilidad de las zonas bajas debido a la pérdida de absorción del suelo en las laderas o zonas altas.

\subsubsection{Indicadores de Impacto}

Los factores que se valoran para la detección de las áreas más expuestas a la erosión -como proceso de degradación ambiental- son el tipo de suelo y su permeabilidad; la pendiente, y la existencia de cobertura vegetal.

Para evaluar el impacto del uso urbano en relación a la erosionabilidad del territorio, se seleccionan inicialmente los sectores con menor permeabilidad según tipo de suelo y pendientes mayores al $15 \%$. Luego se integraron las áreas que no poseen vegetación. El cuadro de impacto elaborado se refiere específicamente a las tres situaciones detectadas para el caso de Río Ceballos que presentan mayor impacto de erosión hídrica.

\begin{tabular}{|l|c|c|c|}
\hline \multicolumn{1}{|c|}{ Grado permeabilidad } & Pendientes & Cubierta Vegetal & Nivel Impacto \\
\hline \multirow{2}{*}{$\begin{array}{l}\text { BAJA O MUY BAJA } \\
\text { Granitos y granitoides }\end{array}$} & Más del 15\% & NO & $\begin{array}{c}\text { ALTO } \\
\text { No apto urbanización }\end{array}$ \\
\cline { 2 - 4 } & Más del 15\% & SI & $\begin{array}{c}\text { MEDIO ALTO } \\
\text { No recomendable }\end{array}$ \\
\hline
\end{tabular}




\begin{tabular}{|l|l|l|l|}
\hline $\begin{array}{l}\text { Gneis tonalítico granitizado } \\
\text { Gneis Tonalítico } \\
\text { Gneis Esquistoso }\end{array}$ & Menos del 15\% & NO & MEDIO \\
\hline
\end{tabular}

\subsubsection{Cartografía de Impacto según erosionabilidad del suelo}

En primer lugar se observa que las áreas que no poseen vegetación y cuentan con elevadas pendientes y baja permeabilidad del suelo se localizan en sectores puntuales dentro de la trama urbana y ocupan pequeñas superficies. Las zonas con mayores pendientes y suelos menos permeables en general poseen vegetación, lo cual previene mayores grados de erosión, sin embargo significan un impacto medio-alto -y manifiestan una gran extensión de superficie-. Dentro de este grupo se incluyen los loteos ubicados dentro de la Reserva Los Manantiales -El Vergel, Agua del Peñón, Manantiales-, como así también Ñu Porá, Terrazas del Río y Pozos Verdes dentro de la Reserva La Quebrada. Estos sectores localizados en la ladera oeste presentan procesos de ocupación urbana del suelo con diversos grados de consolidación.

Finalmente, se evidencian zonas sin vegetación y baja permeabilidad del suelo que presentarían un impacto ambiental medio. Se trata de áreas con bajas pendientes que forman parte de la mancha urbana consolidada.
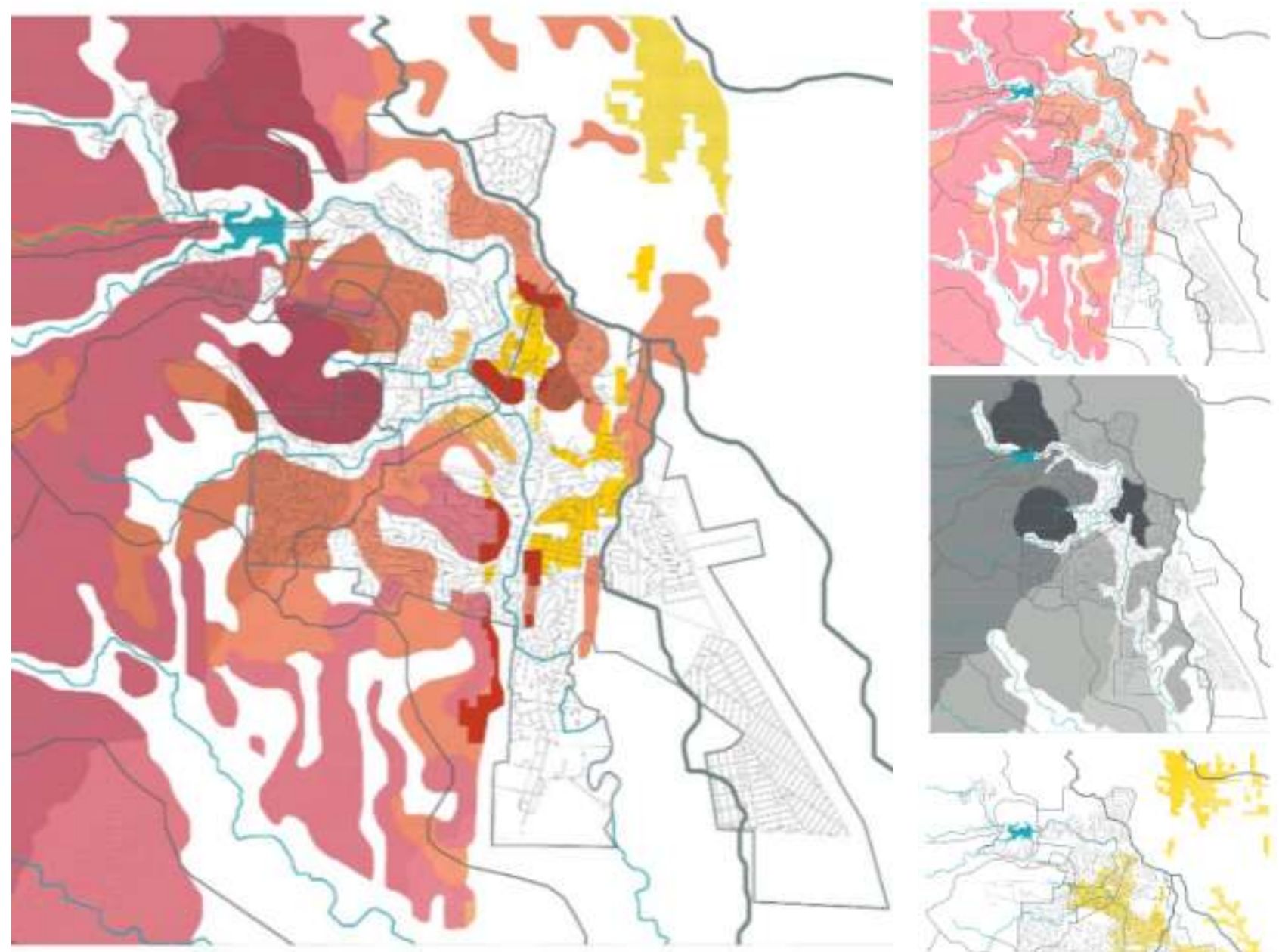

$>$ EAOBIONABIUDAO ESC. 1:S0000
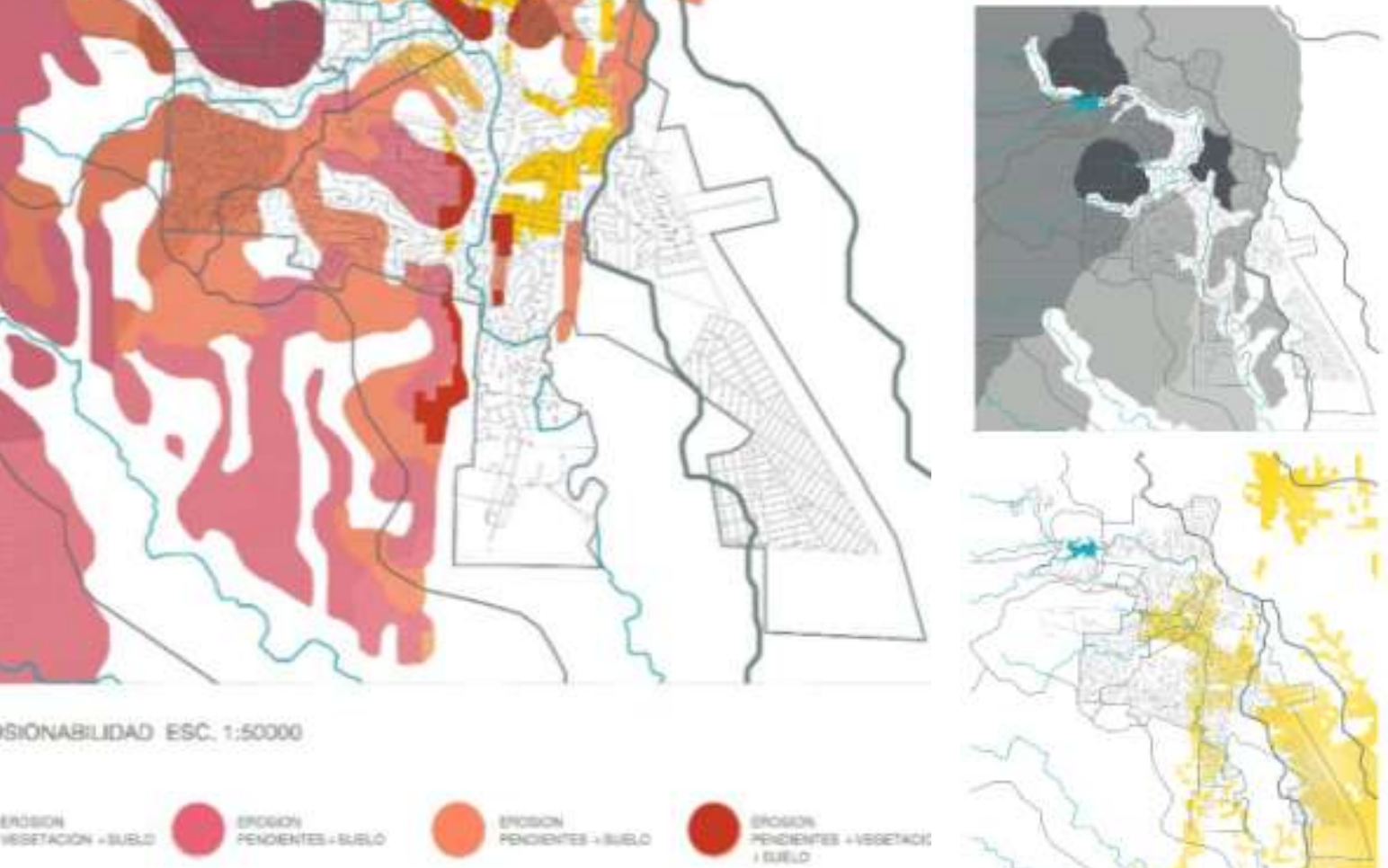

Cartografía impacto uso urbano según erosionabilidad. Fuente: Elaboración propia

\subsection{Agua}

\subsubsection{Caracterización Hidrológica}


Una primera consideración para abordar la hidrología de Sierras Chicas y Río Ceballos es la comprensión del área de estudio dentro del sistema de cuencas hídricas. Las cuencas de la ladera oriental de las Sierras Chicas forman parte de la vertiente oriental y pertenecen al sistema endorreico que tienen como nivel de base la Laguna de Mar Chiquita. El área urbana de la localidad de Río Ceballos está principalmente comprendida en la subcuenca del arroyo Saldán, la cual a su vez pertenece a la cuenca del Río Primero. El sector norte de la localidad de Río Ceballos forma parte de la cuenca del Río Salsipuedes.

El sistema hídrico del área presenta un régimen pluvioestival irregular cuyos ríos y arroyos se caracterizan por tener escasa longitud y alta torrencialidad. Las escorrentías superficiales o excedentes de agua de lluvia en muchos casos conforman cauces temporarios en las laderas serranas. El caudal de las escorrentías depende de varios factores: la cantidad de agua llovida -duración e intensidad-, el tipo de suelo, la pendiente, y la presencia o no de cobertura vegetal, los cuales determinan el grado de infiltración de agua. La cobertura vegetal nativa le resta velocidad a la escorrentía superficial permitiendo que a través de sus raíces al agua ingrese a los niveles inferiores de suelo facilitando su infiltración y disposición en períodos de bajas precipitaciones, en los cauces de ríos y arroyos. "La deforestación, la impermeabilización y el remplazo de cobertura vegetal nativa contribuye a la escorrentía superficial"(Deón, 2015:7).

\subsubsection{Inundabilidad}

En el área de estudio, los cursos de agua son elementos centrales en la identidad ambiental y cultural de la ciudad; asociados tanto al origen del asentamiento urbano como a su calidad paisajística y ambiental. Sin embargo, uno de los impactos urbanos está vinculado al riesgo de inundación de las áreas colindantes a los cauces. Se manifiesta un avance de urbanizaciones e infraestructuras informales sobre el cauce del Río Ceballos que producen modificaciones en el trazado del mismo. De esta manera se reduce su ancho y se obstruye el cauce natural. Estas trasformaciones se han agudizado a partir de las inundaciones ocurridas en 2015, debido a que los frentistas han construido diversas contenciones para la protección de las propiedades sin contar con estudios de línea de ribera.

Existen normativas que plantean restricciones a las edificaciones en relación a riesgos hídricos.

- La Ley Provincial de loteos 4146 (1949) establece para nuevas urbanizaciones la obligación de generar un espacio no urbanizable con una distancia de $30 \mathrm{~m}$ a partir de la línea más alta de creciente en períodos normales, pero que puede ser ocupada por avenidas de $20 \mathrm{~m}$.

- La Resolución 395-04 (2004) establece un "deslinde provisorio" en caso de omitir el cálculo de la línea de ribera. El Río Ceballos queda incluido en una categoría que establece un retiro mínimo de $12 \mathrm{~m}$ medidos desde el eje del cauce permanente. Estos retiros no afectan los derechos posesorios.

Sin embargo, para establecer con precisión las áreas de riesgo hídrico es necesario contar con los estudios hidráulicos e hidrológicos que incorporen los caudales registrados en la última inundación 2015.

\subsubsection{Cartografía de Impacto según inundabilidad}

Para evaluar el impacto de uso urbano en relación a la inundabilidad sobre los márgenes de cauces permanentes, se toman como referencia los datos establecidos por las normativas provinciales; determinando inicialmente un área buffer (1) de 24metros según línea de ribera -12metros desde el eje de cauce hacia ambos márgenes-. Si se considera este límite como promedio de las máximas crecidas, luego puede determinarse un área buffer (2), referido a los 30 metros de espacio no urbanizable según la Ley Provincial de 1949. El área buffer total considerado es de 84metros.

Para la elaboración de las cartografías de impacto de uso urbano en relación a la inundabilidad se propone comparar el buffer normativo con el área real afectada en la inundación 2015 según relevamiento municipal. Respecto a los cursos de agua temporaria se toma como referencia la normativa municipal vigente en Reserva Hídrica Municipal Los Manantiales (2014), la cual establece un área buffer de 15 metros medidos desde la línea municipal de la parcela frentista, con restricción a edificaciones.

\begin{tabular}{|l|l|l|}
\hline & Aptitud & Nivel Impacto \\
\hline Cauce Temporario: Área Buffer 15m (L. Municipal) & No apto & ALTO \\
\hline Cauce Permanente: Área Buffer 84m (Eje Cauce) & No apto & ALTO \\
\hline Áreas afectadas por inundación 2015 & No apto & ALTO \\
\hline Áreas no afectadas por cauces & Apto & BAJO \\
\hline
\end{tabular}

Impacto según inundabilidad. Fuente: Elaboración propia.

\subsubsection{Conclusión cartografía de impacto inundabilidad}


La superposición del área de restricción establecida por normativa y del área afectada por inundación en 2015, materializa un polígono de riesgo hídrico sobre el Río Ceballos que en muchos casos supera ampliamente la franja de 84 metros reglamentaria. Se verifica que el area inundable abarca en zonas específicas un margen de hasta 300 metros del curso de agua. Por otro lado, se evidencia que las edificaciones invaden ampliamente las áreas buffers normativas, incluso los retiros mínimos establecidos como línea de ribera provisoria. Esta desconsideración del sistema hídrico en los modos de ocupación urbana incluye los cauces secundarios y las escorrentías temporarias. Se observa que la zona sur de la localidad y el área urbana de la Reserva Los Manantiales aun presentan sectores no consolidados donde es posible aplicar áreas buffer de restricción urbana.
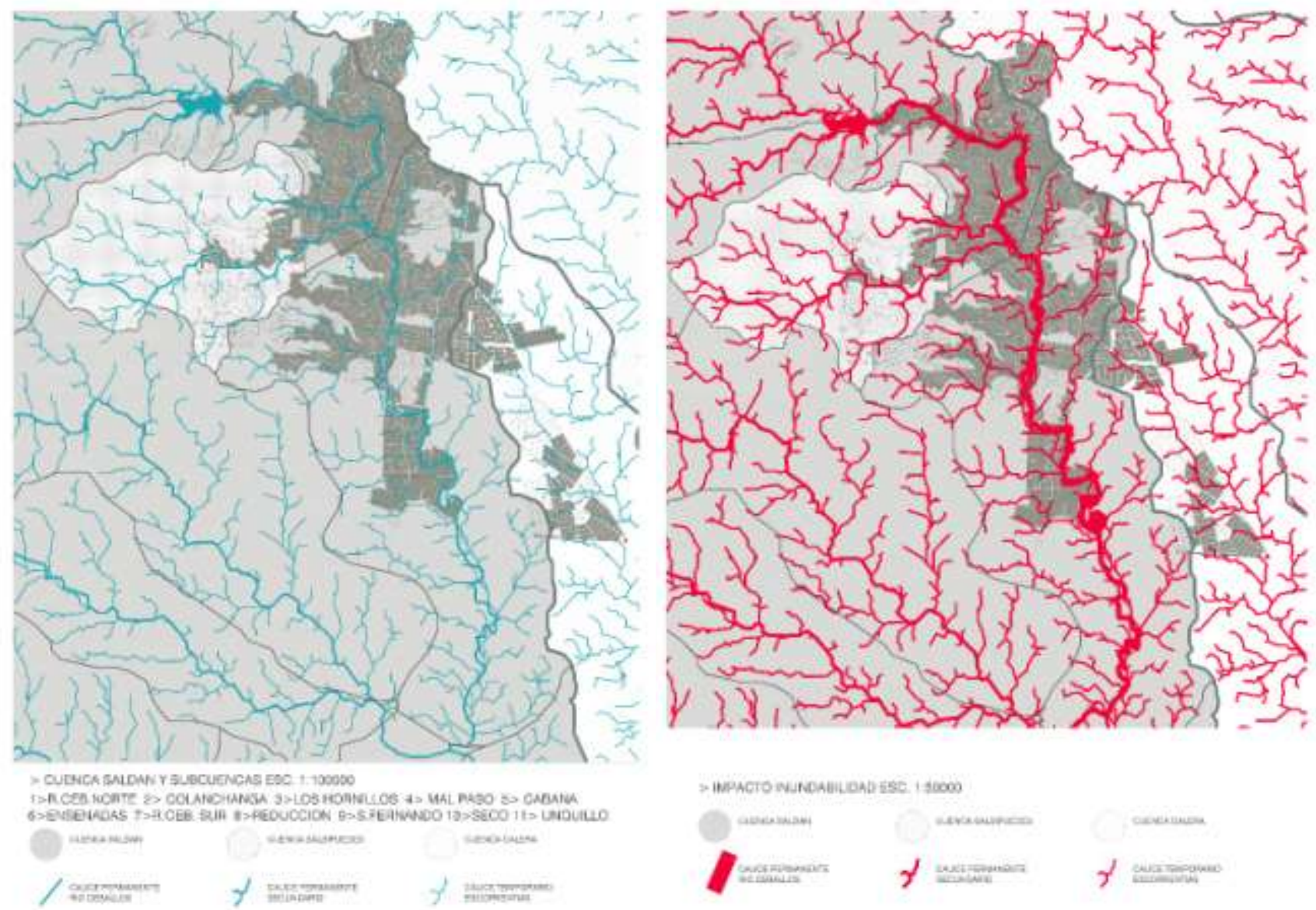

Cartografía impacto uso urbano según inundabilidad. Fuente: Elaboración propia

\section{CONCLUSIONES PRELIMINARES}

El estudio de las variables del soporte natural seleccionadas -vegetación, suelo, agua- y su vinculación con la mancha urbana actual permitió detectar las áreas donde el uso urbano provoca mayor impacto territorial. La superposición de las diferentes capas de análisis evidencia que éstas áreas se concentran en la ladera oeste de la localidad como parte del piedemonte serrano. La baja permeabilidad del suelo y las elevadas pendientes que superan el $15 \%$ en la mayoría de los casos, determinan un elevado riesgo de erosión hídrica. Estos sectores aún conservan bosque como cobertura vegetal predominante. La presencia de cauces secundarios y escorrentías superficiales advierten sobre el riesgo de inundabilidad. En algunos casos estas zonas de alta fragilidad ambiental forman parte de las reservas naturales de la localidad: Reserva Hídrica Municipal Los Manantiales y Reserva Provincial La Quebrada. En ambos casos las reservas incluyen áreas urbanas con diferentes grados de consolidación: el loteo Pozos Verdes aun inactivo en la reserva provincial y los loteos El Vergel, Agua del Peñon, Los Manantiales, y parte de Ñu Pora en la reserva municipal. Otros loteos que se localizan en el piedemonte serrano y significan un alto impacto territorial son los loteos Terrazas del Río y Ñu Pora al sur y San Francisco, María Cristina y Parque Río Ceballos al norte de la localidad.

Finalmente un sector que presenta un alto impacto territorial de acuerdo a las variables estudiadas es el faldeo sur del camino al cuadrado - La Lucinda, Río Ceballos Norte y Nogales Norte-. 
La cartografía, como herramienta metodológica permitió sistematizar información interdisciplinaria disponible y vincularla al territorio. A partir de las problemáticas detectadas, y las variables de estudio seleccionadas, el análisis permitió cuantificar y objetivar los posibles impactos territoriales a partir del uso urbano.

Este análisis permite aplicaciones concretas en la planificación urbana y en los procesos de decisión sobre el territorio. En particular posibilita; El reconocimiento de áreas de riesgo ambiental en sectores ya consolidados con uso urbano, previendo medidas que mitiguen el impacto ocasionados por la actividad; La detección de áreas hacia donde el uso urbano no debe expandirse, ya sea áreas no loteadas, o áreas loteadas no ocupadas. En este ultimo caso existen herramientas técnicas y de gestión que pueden aplicarse para minimizar o anular el impacto que produciría el uso urbano.

BIBLIOGRAFIA

Barbeito, O., Ambrosino, S., \& Quintana Salvat, F. (2009, octubre). Carta Geológica y Geomorfológica como Base para la Evaluación, Mitigación de Riesgos y la Planificación Territorial. Instituto Nacional del Agua. Centro de la Región Semiárida.

Cioccale, M. (1999). Investigación geomorfológica de cuencas serranas. Estudio geomorfológico integral: morfodinámica, morfometría y morfogenesis del flanco oriental de las Sierras Chicas (Tesis Dotoral). Universidad Nacional de Córdoba. FCEFyN, Córdoba.

Deón, Joaquín. (2015). Aportes para el entendimiento de las inundaciones recientes en Sierras Chicas.

Sierras Chicas entre baja disponibilidad de agua y crecidas de arroyos. Recorte del trabajo de investigación: Conflictos por el agua y el uso del suelo en las Sierras Chicas. El caso de la cuenca del río Chavascate. 2014.

Gavier, G., \& Bucher, E. (2002). Deforestación y fragmentación del bosque en las Sierras Chicas de Córdoba, Argentina (Tesis de Maestría). Universidad Nacional de Córdoba, Facultad de Ciencias Exactas Físicas y Naturales, Córdoba.

Gómez Orea, D., \& Gómez Villarino, M. T. (2013). Evaluación de impacto ambiental. Madrid: Mundi-Prensa. McHarg, I. L. (2000). Proyectar con la naturaleza. Barcelona: G. Gili.

Tecco, C., \& Fernández, S. (2002). Los cambios sociales y espaciales en municipios de la periferia urbana de Córdoba: nuevos desafíos de gestión metropolitana. IV Seminario Nacional de Redmuni.

Terreno, C. (2010). Proceso de crecimiento de las localidades del Área Metropolitana de la ciudad de Córdoba. El caso de Río Ceballos (Tesis de Maestría). Universidad Nacional de Córdoba. FAUD. Maestría en Gestión Ambiental, Córdoba.

Villoslada, B. (2003). Estudio geológico- geomorfológico del área urbana y suburbana de Río Ceballos. Facultad de Ciencias Exactas, Físicas y Naturales. Geología UNC, Córdoba.

\section{Ordenanzas}

Ley Provincial de Loteos 4146. (1949). Cámara de Diputados de la Provincia de Córdoba. Octubre 1949. Córdoba.

Ordenanza Reserva Hídrica Natural Municipal Los Manantiales 2094/14. (2014). Concejo Deliberante Río Ceballos. Junio 2014. Río Ceballos, Córdoba.

Resolución 395-04 Línea de Ribera. (2004). Dirección Provincial de Agua y Saneamiento, Gobierno de la Provincia de Córdoba. Agosto 20004. Córdoba.

\section{Fuentes electrónicas}

http://www.lavoz.com.ar/ciudadanos/en-2050-solo-quedara-la-mitad-de-bosque-en-las-sierras-chicas (Consulta 24/02/2018). 
